\title{
The Boring Sounding of Alluvial Soils
}

\author{
Gennadii Boldyrev ${ }^{1}$, Gennadii Novichkov ${ }^{2}$ \\ Department Civil Construction, Penza State Architecture and Construction University, Penza, Russia \\ E-mails: ${ }^{I}$ g-boldyrev@geoteck.ru (correspondingauthor); ${ }^{2} g n @ s$-teh.biz
}

\begin{abstract}
In article the description and results of in situ test of soils is resulted by of Russian drilling test (RDT). It involves several drilling parameters: torque, axial force, rotation speed, linear velocity, tip resistance for identifying soil strata of different strengths and for determining dependences between drilling parameters and soil deformation properties.
\end{abstract}

Keywords: Russian drilling test, drilling parameter, torque, axial force, rotation speed, linear velocity, tip resistance allocation layers of soils, technical means, module deformation.

Conference topic: Soil and rock investigation.

\section{Introduction}

Lately, one of the most popular methods of in-situ soil tests is static penetration test. It is widely used both in Russia and abroad while conducting soil investigations.

Over the last years, penetration equipment was substantially improved i.e. wireless data transmission systems are used to transmit data on the top of the ground, continuous CPT systems for continuous rod adding, cone health monitoring system etc. However, there are still some problems connected with limited resources and the loss risk of expensive cones. Thus, skilled professionals with large experience in site investigations bring Russian drilling test (RDT) (Boldyrev et al. 2012) back to memory even more frequently.

RDT was primarily introduced by the engineers of PNIIIS (www.pniiis.ru) in 1989. Based on its results soil was divided into different layers, the accuracy of these results was proved by well bore sampling.

RDT has many advantages comparing to other insitu soil testing methods including cone penetration test. These are:

- control of speed rotation and axial loading;

- high depth of penetration;

- measuring equipment safety: sensors are not penetrated into the soil, thus, are not damaged by solid inclusions (gravel, cobble, fragments of concrete);

- measuring equipment safety, that allows penetrating in offshore areas;

- no need to use heavy drilling equipment;

- ability to conduct researches of soil as well as rocks and permafrost.

\section{Equipment}

Modern technologies such as computers, microprocessors, laser ranging and wire-less communication allow taking advantage of RDT method creating data measuring system for drilling machines to measure rotating torque, vertical load affecting drilling tools, rotation speed, penetration depth.

The data measuring system (Fig. 1) developed by engineers NPP Geotek Ltd (www.npp-geotek.com) consists of the following items: vertical load sensor; rotating torque sensor; laser ranging sensor for screw motion measuring; digital amplifier for sensors; wireless data transmission unit; notebook and software.

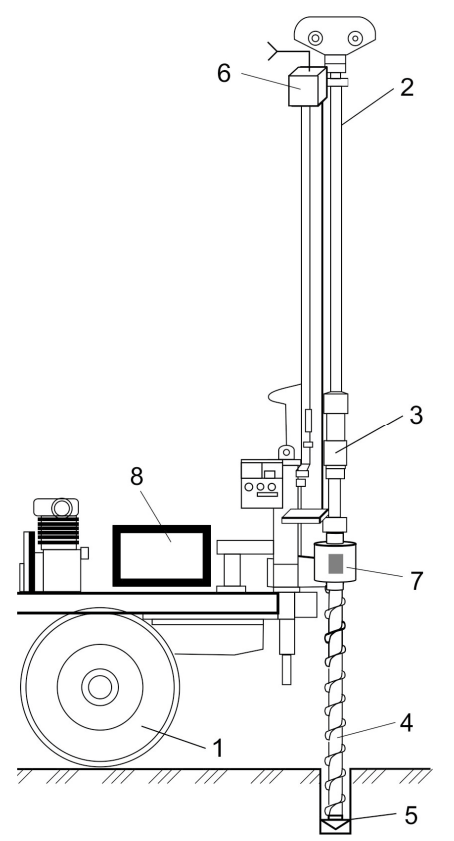

Fig. 1. Drilling rigs equipped with measuring system

A series of tests were carried out to evaluate system properties to identify soil layers. Drilling was made by bore bit of diameter $150 \mathrm{~mm}$ with different ware rate.

The test results are given in Figure 2. The system makes an interpretation of the depth and consistency of soil layers depending on capacity (speed rate of boring tool and vertical load) to drilling depth. Penetration test of a testing well bore shown in Figure 2 were made at a 
lowered speed of rotation head. Vibrational perturbations of rotating torque were observed.

\section{Methods \\ Identification of soil layers}

The system used for drilling sensing consists of a vehicle, a drilling mast, a rotary head, a drill string, a boring bit, a data-measuring system. Soil tests made using this system (Fig. 2) are conducted as follows.

The vehicle along with drilling sensing machine (Fig. 2) is placed on an investigated site.

The drilling mast with a rotary head on it is raised. The shank of the sensor unit is inserted into the holder and connected to the shank of the auger flight with the drill bit fixed on its lower end.

A ranging laser and the deflector are fixed on the mast. A PC and a self-contained power supply of the laser and the measuring unit are turned on, and then the process of drilling a well starts. Well drilling is conducted at a constant speed of $\omega$.

The following data are recorded in the database in the process of sensing: time of penetration $(t)$, vertical load $(F)$, torque $(M)$, rotational rate $(\omega)$ and vertical displacement of the drill string $(s)$.

Using the results of measurements the following parameters are calculated:
- general vertical load:

$$
N=F+G,
$$

where: $F$ - vertical load measured by vertical load sensor; $G$ - the weight of the drill string;

- advance speed of drilling tool:

$$
V=\frac{\Delta s}{\Delta t},
$$

where: $\Delta s$-vertical displacement of drill string from the moment of previous record; $\Delta t-$ time of penetration within the distance $\Delta s$;

- load power at a current drilling depth:

$$
P_{v}=N \cdot v
$$

where $N$ - general vertical load; $v$ - current advance speed of drilling tool;

- rotation power at a current depth:

$$
P_{\omega}=2 \pi M \omega
$$

where: $M$ - current torsion torque; $\omega$ - rotational rate of drilling tool.

The total power at a current depth:

$$
P_{t}=P_{v}+P_{w}
$$

where: $P_{v}-$ load power; $P_{\omega}-$ rotation power.
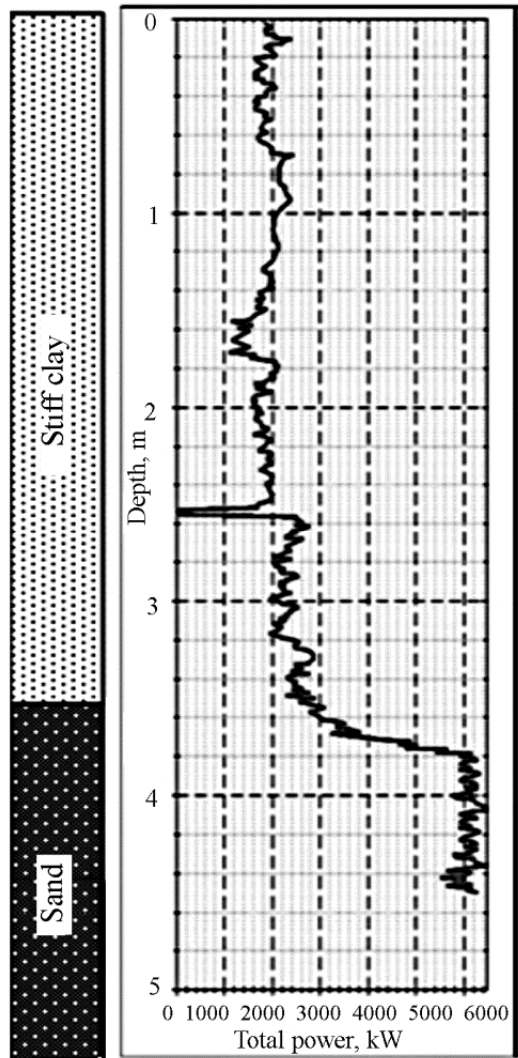
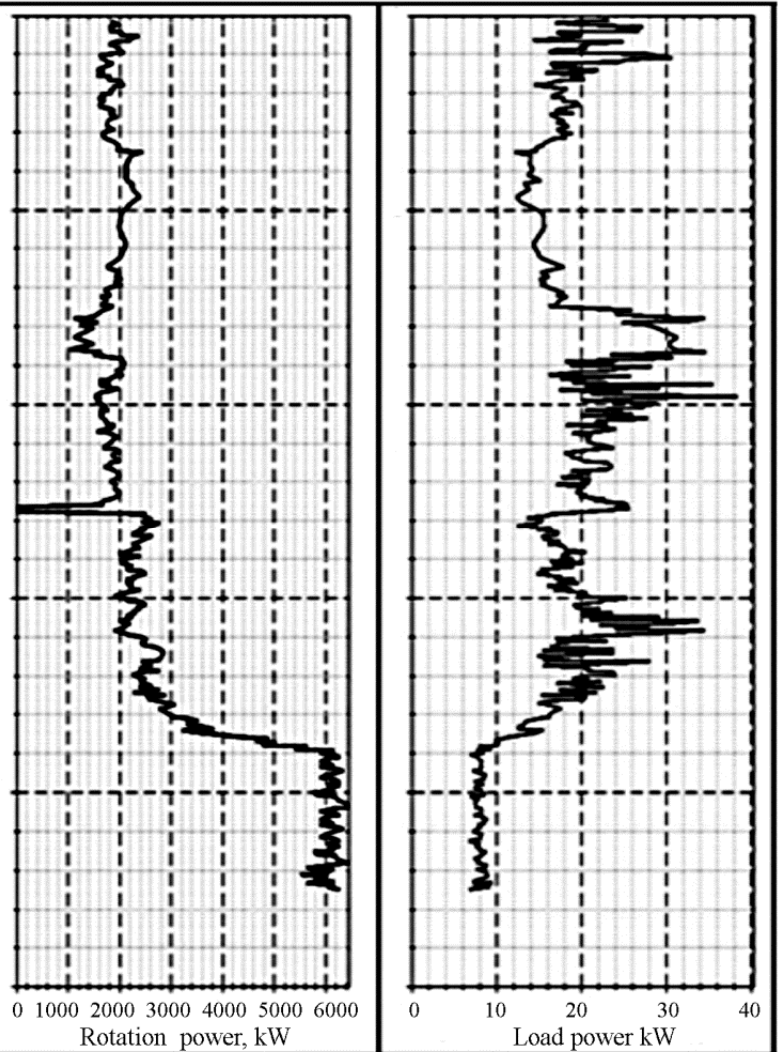

Fig. 2. RDT log with subsurface stratigraphy interpretation 
Figure 2 shows a RDT $\log$ for different soils, natural clays, and sands. The soil classification column based on GOST 25100. To develop a profile for design, distinct breaks in the RDT data should be reviewed. A review of Figure 2 indicates that a significant change in material type occurs at approximately a depth of $2 \mathrm{~m}$ as defined by a growth in rotation and load power. These trends indicate that at this depth the RDT has penetrated into a clay unit characterized by increased power. These trends in the data indicate that a clay material has been encountered. Also shown on this profile are CPT test data from an adjacent location. Thus, the RDT characterization presented here is consistent with the CPT results (Fig. 3).

Some researchers should be made to select effective drilling technique: rotational rate of speed, penetration load, type of drilling tool.

\section{Definition of soil deformation modulus}

The drilling rig is placed on an investigated site, the drilling mast with a rotary head on it is raised, the shank of the sensor unit is inserted into the holder of the drilling rig, adapter is putted into drill rod or into auger flight, the ranging laser and the deflector are fixed on the mast, the PC and the self-contained power supply of the laser and the measuring unit are turned on, and then the process of drilling starts.

At a target depth of deformation modulus defining dummy spinning of drilling string is made and the string is raised at a height of $10-20 \mathrm{~cm}$ above face of the well, then the boring head of drilling rig is turned on.

Cumulative weight of the drilling string and of the soil at the lateral side of drilling string is measured by means of a load sensor:

$$
Q=G+G_{1},
$$

where: $G$-weight of the drill string; $G_{1}$ - weight of the soil at the lateral side of drilling string.

Drilling string is run to the bottom and using a sensor unit with a servo driver the first stage of the pressure level is imposed. To define its value we use the following expression:

$$
p_{0}=\gamma z+\frac{Q}{A}
$$

where: $A$ - cross sectional area of drill bit; $\gamma-$ specific weight of soil; $z$ - depth from the soil surface to the deformation measuring point.

While loading vertical displacement (settlement) of the drilling string is measured using a ranging laser and a load sensor and stability of target pressure rate $\left(p_{i}\right)$ is controlled by means of a stepped motor and a load sensor.

After stabilization of the first loading stage settlement its value is recorded into the database, computerinitiated the motor starts and the pressure stage is imposed:

$$
p_{i}=p_{o}+\Delta p_{i}
$$

Then, tests are carried out until the value of cumulative pressure equal to $p_{i}=p_{0}+\gamma z$ is obtained.
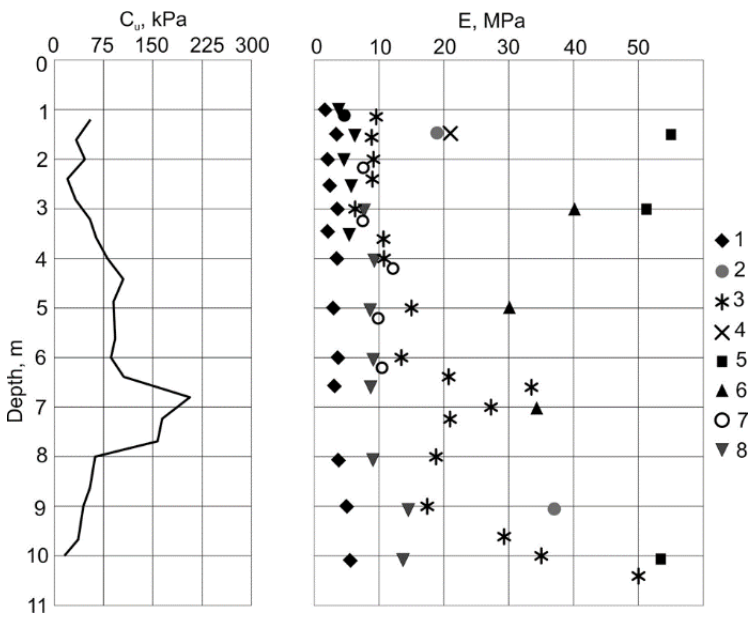

Fig. 3. Comparison of modules deformation from different tests: 2 - triaxial test; 3 - CPT; 4 - plate load test $\left(5000 \mathrm{sm}^{2}\right)$; 5 - Russian screw test $\left(600 \mathrm{sm}^{2}\right) ; 6$ - RDT; 7 - Russian stiff dilatometer (Boldyrev et al. 2015); 1, 8- oedometer test

Using the measuring we can draw a diagram of dependence of drilling string vertical displacement on pressure $s=f(p)$ and by means of Schleicher's solution deformation modulus can be calculated:

$$
E_{R D T}=\frac{\theta \cdot \Delta p \cdot\left(1-v^{2}\right)}{\Delta s},
$$

where: $\theta$ - ratio depending on drill bit; $\Delta p$ - pressure increment on a straight line portion $s=f(p)$; $v_{-}$ Poisson's ration for this soil type; $\Delta s$ - settlement increment within a selected range of pressure increment $\Delta p ; d$-diameter of drill bit.

Value of $\theta$ - ratio can be found using correlation by means of this tests along with triaxial soil testing for each type of drill bid (twin-bladed, triple-bladed, rolling cutter bit etc.) Samples are cut out of the monoliths sampled from soil massive at the same testing depth.

\section{Conclusions}

Investigation results show expedience and effectiveness of drilling sensing method while defining soil layers in natural soils. After accumulating correlation relations in different soil layers this method can be recommended for defining deformation modulus by means of an auger while drilling a well.

\section{References}

Boldyrev, G.; Kalbergenov, R.; Kushnir, L.; Novichkov, G. 2012. Boring sounding of soil, Geotechnical Investigations 12: 38-42 (in Russian).

Boldyrev, G.; Guskov, I.; Lavrov, S.; Sidorchuk, V.; Skopintsev, D. 2015. Comparison of soil test data, obtained with different probes, in $3^{\text {rd }}$ International Conference on the Flat Dilatometer DMT'15, 14-16 June 2015, Roma, Italy, 359-362. 